\title{
Role of oral micronized progesterone versus vaginal progesterone for prevention of preterm labour
}

\author{
Neeta Natu, Shikha Sonker*, Nootan Chandwaskar, Sweta Agrawal
}

Department of Obstetrics and Gynecology, Sri Aurobindo Institute of Medical Sciences, Indore, Madhya Pradesh, India

Received: 17 March 2017

Accepted: 22 March 2017

*Correspondence:

Dr. Shikha Sonker,

E-mail: shikhasonker19@yahoo.in

Copyright: () the author(s), publisher and licensee Medip Academy. This is an open-access article distributed under the terms of the Creative Commons Attribution Non-Commercial License, which permits unrestricted non-commercial use, distribution, and reproduction in any medium, provided the original work is properly cited.

\section{ABSTRACT}

Background: Preterm birth remains a significant problem in obstetric care, affecting women and babies world-wide. Progesterone has an essential role in maintaining pregnancy by suppression of the calcium-calmodulin-myosin light chain kinase system. This study reflects the use of progesterone in preventing preterm birth.

Methods: The data were collected as a retrospective study from SAMC and PGI Obstetric and Gynaecology Department.

Results: With the use of Oral micronized progesterone out of 15 cases, term delivery 9 cases i.e. $60 \%$ and preterm delivery 6 cases i.e $40 \%$ and, with the use of vaginal progesterone suppository out of 15 cases, term delivery 11 cases i.e. $73.3 \%$, preterm delivery only 4 cases i.e $26.7 \%$.

Conclusions: Progesterone appears to be safe and efficacious in reducing the risk of preterm birth as well as NICU admissions, and neonatal morbidity and mortality in high risk patients. However, there is limited information available relating to longer-term infant and childhood outcomes, the assessment of which remains a priority. Further, trials are required to assess the optimal timing, mode of administration and dose of administration of progesterone therapy when given to women considered to be at increased risk of early birth.

Keywords: NICU, Preterm birth, Preterm delivery, Progesterone, Vaginal progesterone

\section{INTRODUCTION}

Preterm labour is the onset of regular uterine contractions associated with progressive cervical change between viability and 37 completed weeks of gestation. ${ }^{1}$ The countries with the highest annual number of preterm births are India (3.52 million), China (1.17 million), Nigeria $(773,600)$, Pakistan $(748,100)$, Indonesia $(675,700)$, and the United States $(517,400){ }^{2}$

Preterm delivery (PTD) is due to either spontaneous preterm labor (PTL) (40\%-50\%), spontaneous preterm premature rupture of membranes (PPROM) (25\%-40\%), or obstetrically indicated PTD $(20 \%-25 \%)$ as a result of maternal, placental or fetal complications (preeclampsia, renal disease, diabetes mellitus with vasculopathy, placenta previa or abruptio, and fetal growth restriction. ${ }^{3}$

The generally accepted pathways of spontaneous PTB include:

- Premature activation of the fetal hypothalamicpituitary axis,

- Infection/inflammation,

- Decidual hemorrhage or ischemia,

- Uterine overdistention, as it occurs with polyhydramnios or multiple gestations. Each of these underlying causes can initiate the cascade of events that ultimately leads to uterine activity and cervical dilation. $^{4}$ 
Infants born preterm are over 40 times more likely to die during the neonatal period than are term infants. ${ }^{5,6}$ While the risk is greatest for infants born at earlier gestational ages, this increased risk of mortality persists even for infants born between 32 and 36 weeks gestation. ${ }^{7}$ For surviving infants, there are significant health implications, particularly in relation to immature lung development, with respiratory distress syndrome being a major consequence of preterm birth and the most significant cause of early neonatal mortality and morbidity. ${ }^{8}$ well-documented health complications include intraventricular hemorrhage and periventricular leukomalacia, with implications for ongoing cerebral dysfunction infectious morbidity, and specific neonatal conditions associated with prematurity, including retinopathy of prematurity and necrotising enterocolitis. Infants continue to be at increased risk of hospitalization in the first year of life. ${ }^{9}$

Progesterone has an essential role in maintaining pregnancy by suppression of the calcium-calmodulinmyosin light chain kinase system. ${ }^{10}$ Thus, primarily through establishing uterine quiescence. Additionally, progesterone has recognized anti-inflammatory properties, raising a possible link between inflammatory processes, alterations in progesterone receptor expression and the onset of preterm labor. ${ }^{11}$

The objectives of the study were

- This study aims to differentiate between effectiveness of oral and vaginal progesterone in cases of preterm labour.

- To study whether use of progesterone is mandatory in cases of preterm birth setting.

\section{METHODS}

It is a retrospective study, conducted in the Shri Aurobindo medical college and PGI at obstetrics and gynaecology department 30 patients were selected which are at high risk for preterm labor and were given progesterone support from 1st trimester. 15 patients were treated with oral micronized progesterone and the rest 15 were treated with Vaginal Suppositories.

\section{Inclusion criteria}

preterm labour upto 37 weeks of gestation, Cardiac Activity present in recent scan, previous H/o preterm labor, previous $\mathrm{H} / \mathrm{O}$ abortions, and patients having $\mathrm{H} / \mathrm{o}$ of infection in present pregnancy, H/o multiple gestation in present pregnancy.

\section{Exclusion criteria}

IUFD, low lying placenta, coagulation disorders, uterine anomalies.

\section{Statistical analysis}

Data was analyzed using Statistical Software Minitab Version 17.0 for Windows. Chi Square test was used to take out the $\mathrm{p}$ value. Value less than 0.05 was considered significant.

\section{RESULTS}

With the use of Oral micronized p out of 15 cases, term delivery 9 cases i.e. $60 \%$ and preterm delivery 6 cases i.e. $40 \%$ and, with the use of vaginal progesterone suppository out of 15 cases, term delivery 11 cases i.e. $73.3 \%$, preterm delivery only 4 cases i.e. $26.7 \%$

Table 1: Oral micronized progesterone use.

\begin{tabular}{|lll|}
\hline $\begin{array}{l}\text { Oral micronized } \\
\text { progesterone use }\end{array}$ & No. of cases & Percent \\
\hline Term & 9 & 60 \\
\hline Preterm & 6 & 40 \\
\hline
\end{tabular}

Table 2: vaginal progesterone use.

\begin{tabular}{|lll|}
\hline Vaginal progesterone use & No. of cases & Percent \\
\hline Term & 11 & 73.3 \\
\hline Preterm & 4 & 2.7 \\
\hline
\end{tabular}

\section{DISCUSSION}

In our present study with the use of vaginal progesterone suppository $26.7 \%$ had preterm delivery, our study is supported by the study of Eduardo B. da Fonseca et al 2003 out of 72 patients given progesterone $21 \%$ has preterm delivery, more women were delivered before 34 weeks in the placebo group $(18.5 \%)$ than in the progesterone group $(2.7 \%)(\mathrm{P}<.05) .{ }^{12}$

Roberta Mackenzie initiated a randomized control trial which suggested that Progestational agents, initiated in the second trimester of pregnancy, may reduce the risk of delivery less than 37 weeks' gestation. ${ }^{13}$

SuLL et al conducted Eight studies which reviewed, involving 563 women, but only seven studies, involving 538 women, contributed data for analyses. There are some data suggesting that the use of progestational agents results in a reduction of preterm deliveries at less than 37 weeks of gestation and an increase in birthweight. The use of a progestational agent may also reduce the frequency of uterine contractions, prolong pregnancy and attenuate the shortening of cervical length. ${ }^{14}$

Dodd JM et al Thirty-six randomised controlled trials (8523 women and 12,515 infants) were included. Progesterone versus placebo for women with a past history of spontaneous preterm birth Progesterone was associated with a statistically significant reduction in the risk of perinatal mortality. Progesterone versus no 
treatment/placebo for women following presentation with threatened preterm labour Progesterone, was associated with a statistically significant reduction in the risk of infant birthweight less than $2500 \mathrm{~g}$ (one study; 70 infants; RR 0.52 , 95\% CI 0.28 to 0.98). Progesterone versus placebo for women with 'other' risk factors for preterm birth Progesterone, was associated with a statistically significant reduction in the risk of infant birthweight less than $2500 \mathrm{~g}$ (three studies; 482 infants; RR 0.48, 95\% CI 0.25 to 0.91$).^{15}$

Rai P et al preterm birth occurred in 29 (39.2\%) women in the oral micronized progesterone group $(n=74)$ compared with $44(59.5 \%)$ in the control group $(n=74$, $\mathrm{P}=0.002)$. Mean gestational age at delivery was higher in the Oral micronized progesterone group (36.1 vs 34.0 weeks, $\mathrm{P}<0.001)$. Fewer preterm births occurred between 28 and 31 weeks plus 6 days in the oral micronized progesterone group (RR 0.20; 95\% CI, 0.05-0.73, P $<0.001){ }^{16}$

\section{CONCLUSION}

Preterm birth remains a significant problem in obstetric care, affecting women and babies world-wide. Progesterone appears to be safe and efficacious in reducing the risk of preterm birth as well as NICU admissions, and neonatal morbidity and mortality in high risk patients. However, there is limited information available relating to longer-term infant and childhood outcomes, the assessment of which remains a priority. Further, trials are required to assess the optimal timing, mode of administration and dose of administration of progesterone therapy when given to women considered to be at increased risk of early birth.

\section{Funding: No funding sources}

Conflict of interest: None declared

Ethical approval: The study was approved by the Institutional Ethics Committee

\section{REFERENCES}

1. Chatterjee J, Gullam J, Vatish M, Thornton S. The management of preterm labour. Arch Dis Child Fetal Neonatal Ed. 2007;92(2):F88-F93.

2. Nour NM. Premature Delivery and the Millennium Development Goal. Rev Obstet Gynecol. 2012;5(2):100-5.

3. Tucker JM, Goldenberg RL, Davis RO, Copper RL, Winkler CL, Hauth JC. Etiologies of preterm birth in an indigent population: Is prevention a logical expectation. Obstet Gynecol. 1991;77:343-7.

4. Peltier MR. Immunology of term and preterm labor. Reprod Biol Endocrinol. 2003;1:122.
5. European community collaborative study of outcome of pregnancy between 22 and 28 weeks gestation. Working group on the very low birthweight infant. Lancet. 1990;336:782-784

6. Chan K, Ohlsson A, Synnes A, Lee DSC, Chien L, Lee SK et al. Survival, morbidity, and resource use of infants of 25 weeks gestational age or less. Am J Obstet Gynecol. 2001;185:220-2.

7. Kramer MS, Demissie K, Yang H, Platt RW, Sauvé $\mathrm{R}$, Liston RJAMA. The contribution of mild and moderate preterm birth to infant mortality. Fetal and Infant Health Study Group of the Canadian Perinatal Surveillance System. 2000;284(7):843-9.

8. Lefebvre F, Glorieux J, St-Laurent-Gagnon $T$. Neonatal survival and disability rate at age 18 months for infants born between 23 and 28 weeks of gestation. Am J Obstet Gynecol. 1996;174(3):833-8.

9. Elder DE, Hagan R, Evans SF, Benninger HR, French NPJ. Hospital admissions in the first year of life in very preterm infants. Paediatr Child Health. 1999;35(2):145-50.

10. Astle S, Slater DM, Thornton S. The involvement of progesterone in the onset of human labour. Eur $\mathbf{J}$ Obstet Gynecol Reprod Biol. 2003;108(2):177-81.

11. Dodd JM. The role of progesterone in prevention of preterm birth, Int J Womens Health. 2009;1:73-84.

12. da Fonseca EB, Bittar RE, Carvalho MH, Zugaib M. Prophylactic administration of progesterone by vaginal suppository to reduce the incidence of spontaneous preterm birth in women at increased risk: a randomized placebo-controlled double-blind study. AJOG;188(2):419-24.

13. Mackenzie R, Walker M, Armson A, Hannah ME. Progesterone for the prevention of preterm birth among women at increased risk: a systematic review and meta-analysis of randomized controlled trials. AJOG.2006;194:1234-42.

14. Su LL, Samuel M, Chong YS. Progestational agents for treating threatened or established preterm labour. Cochrane Database Syst Rev. 2014;(1):CD006770.

15. Dodd JM, Jones L, Flenady V, Cincotta R, Crowther CA. Prenatal administration of progesterone for preventing preterm birth in women considered to be at risk of preterm birth. Cochrane Database Syst Rev. 2013;(7):CD004947

16. Rai P, Rajaram S, Goel N, Ayalur Gopalakrishnan R, Agarwal R, Mehta S. Oral micronized progesterone for prevention of preterm birth. Int $\mathbf{J}$ Gynaecol Obstet. 2009;104(1):40-3.

Cite this article as: Natu N, Sonker S, Chandwaskar N, Agrawal S. Role of oral micronized progesterone versus vaginal progesterone for prevention of preterm labour. Int J Reprod Contracept Obstet Gynecol 2017;6:1797-9. 